\title{
Mating induces the expression of immune- and pH-regulatory genes in the utero-vaginal junction containing mucosal sperm-storage tubuli of hens
}

\author{
Mohammad Atikuzzaman ${ }^{1}$, Ratnesh Mehta Bhai ${ }^{1}$, Jesper Fogelholm², Dominic Wright ${ }^{2}$ \\ and Heriberto Rodriguez-Martinez ${ }^{1}$ \\ Linköping University, ${ }^{1}$ Department of Clinical and Experimental Medicine, Faculty of Medicine and Health Sciences \\ and ${ }^{2}$ Department of Physics, Chemistry and Biology, Faculty of Science and Engineering, Campus HU/US, \\ Developmental Biology, Lasarettsgatan 64/65, Lanken, Floor 12, SE-581 85 Linköping, Sweden
}

Correspondence should be addressed to H Rodriguez-Martinez; Email: heriberto.rodriguez-martinez@liu.se

\begin{abstract}
The female chicken, as with other species with internal fertilization, can tolerate the presence of spermatozoa within specialized spermstorage tubuli (SST) located in the mucosa of the utero-vaginal junction (UVJ) for days or weeks, without eliciting an immune response. To determine if the oviduct alters its gene expression in response to sperm entry, segments from the oviduct (UVJ, uterus, isthmus, magnum and infundibulum) of mated and unmated (control) hens, derived from an advanced inter-cross line between Red Junglefowl and White Leghorn, were explored $24 \mathrm{~h}$ after mating using cDNA microarray analysis. Mating shifted the expression of fifteen genes in the UVJ (53.33\% immune-modulatory and $20.00 \% \mathrm{pH}$-regulatory) and seven genes in the uterus, none of the genes in the latter segment overlapping the former (with the differentially expressed genes themselves being less related to immune-modulatory function). The other oviductal segments did not show any significant changes. These findings suggest sperm deposition causes a shift in expression in the UVJ (containing mucosal SST) and the uterus for genes involved in immune-modulatory and pH-regulatory functions, both relevant for sperm survival in the hen's oviduct.

Reproduction (2015) 150 473-483
\end{abstract}

\section{Introduction}

Following natural mating in chicken, a subpopulation of selected spermatozoa is stored for up to several weeks in the sperm-storage tubuli (SST), the primary sperm reservoir located in the mucosa of the utero-vaginal junction (UVJ) segment of the oviduct (Bakst 2011), while the rest of the ejaculate is voided from the vagina. The SST-stored spermatozoa maintain integrity and potential fertilizing capacity by mechanisms yet unknown. The motility of spermatozoa from chickens, turkeys and quails is inhibited by decreasing the $\mathrm{pH}$ level - an effective way to provoke sperm quiescence in vitro (Holm et al. 1996, Holm \& Wishart 1998) and similar to what occurs in the male- (epididymal cauda) and female(oviduct) sperm reservoirs in mammals (RodriguezMartinez 2007). However, whether there are any genes involved in $\mathrm{pH}$ regulation in vivo has not been investigated. Stored spermatozoa are released from the SST to be present alongside the entire oviduct transported by anti-peristalsis to reach the secondary reservoir in the infundibulum, where fertilization of the ova occurs (Brillard 1993, Bakst 2011, Sasanami et al. 2013). Sperm SST-release has been considered a continuous event where aliquots of the stored sperm subpopulation leave the SSTs in relation to various factors, from aquaporin changes in the SST epithelium (Bakst 2011) to ovulation-related progesterone stimuli (Ito et al. 2011, Sasanami et al. 2013).

Spermatozoa and seminal proteins are antigenic to the female immune system, and should therefore be promptly rejected (Das et al. 2009). Moreover, immunecompetent cells for acquired immunity, namely macrophages, antigen-presenting cells expressing MHC class II, $\mathrm{CD}^{4+}$ and $\mathrm{CD}^{8+} \mathrm{T}$ cells and premature $\mathrm{B}$ and plasma cells have been localized to the mucosal tissue of all avian oviductal segments (Das \& Isobe 2008). However, those spermatozoa that survive in the SST seem tolerated by the female during their permanence in the oviduct. In mammals, seminal plasma plays an important role for sperm survival in the female reproductive tract (Robertson 2007) despite its antigenic nature, potentially owing to its immune-modulatory 
properties that might culminate in a state of functional immune tolerance to paternal antigens (Robertson et al. 1997). Such interplay is likely to rely on differential gene expression by the female, either through genes acting on sperm survival or on those involved in immune tolerance. The arrival of spermatozoa to the oviduct leads to changes in its transcriptome or proteome profile as determined in mice (Fazeli et al. 2004) and pigs (Georgiou et al. 2007). In turkeys, sperm artificial insemination (AI) up-regulated threefold the expression of avidin mRNA in SSTs (Long et al. 2003). In chickens, the expressions of transforming growth factor $\beta$ (TGF $\beta$ ) and TGF $\beta$ - receptors (TBRs) are increased within $24 \mathrm{~h}$ after insemination (Das et al. 2006). The authors suggested this enhanced gene expression may suppress anti-sperm immune reaction possibly protecting sperm in the SST. In contrast, avian $\beta$-defensin, an important factor for innate immunity, is expressed in the mucosa of all oviductal segments; the expression being highest in the vagina and lowest in the SST, suggesting the immune response against pathogens or spermatozoa varies within the tract (Abdel-Mageed et al. 2008). A genome-wide gene expression analysis using an oligonucleotide microarray has shown differential expression of transcripts such as Neuropeptide Y, Enah/Vasp-like and of trafficking kinesin-binding protein 1 (responsible for short- and long-term sperm survival) in the SST of Tsaiya Ducks (Huang et al. 2011). The mRNA expression of immune-reactive IL1B and LITAF is increased in the vagina up to $6 \mathrm{~h}$ after $\mathrm{Al}$ in chicken but remains unchanged in the other oviductal segments, indicating that Al can influence the immune reactivity in the vagina but not necessarily in the SST (Das et al. 2009). However, information is still lacking as to how the sperm-oviduct interaction post-mating results in sperm survival with intact fertilization potential. We therefore tested the hypothesis that there is a relatively rapid modulatory gene expression shift in the female oviduct that can promote or inhibit their homeostatic action (thereby affecting sperm motility by $\mathrm{pH}$ regulation at the UVJ containing mucosal SST) and their immune system to tolerate the presence of allogeneic spermatozoa in the oviduct for lengthy periods. Gene expression changes were explored using cDNA microarray analysis of various segments of the oviduct of hens, comparing un-mated (control) hens to those mated to fertile roosters.

\section{Materials and methods}

\section{Animals and sources of oviductal segments}

The chickens used in this study were derived from an advanced inter-cross line (RJF/WL-L13, 9th generation) between a White Leghorn layer breed (WL-L13, a high egg-laying bird) and Red Junglefowl (RJF, the wild progenitor of the modern chicken with a low laying rate); see Johnsson et al. (2012) for details of the cross and breeds used as well for details on rearing and breeding routines. Briefly, all advanced inter-cross line chickens were kept separated by gender at the poultry facilities of Linköping University. Food and water were available ad libitum and the chickens were held under controlled temperature and light regimes (12h light: $12 \mathrm{~h}$ darkness cycle, 5 lux) in 1-2 $\mathrm{m}^{2}$ pens depending on age for their first 7 weeks, in compliance with European Community (Directive 2010/63/EU) and Swedish (SJVFS 2012:26) current legislation. Throughout all experiments, animals were handled carefully and in such a way to avoid any unnecessary stress. Semen from sexually mature, proven fertile roosters was collected by manual abdominal massage to confirm their semen quality prior to experimental mating with sexually mature hens. The semen was primarily extended with Dulbecco's medium $(1: 10 \mathrm{v} / \mathrm{v})$ and examined in four replicates for sperm concentration and kinematics using a light microscope equipped with a thermal plate $\left(41^{\circ} \mathrm{C}\right)$, positive phase contrast optics $(10 \times$ objective), a Charge Coupled Device (CCD) camera (UI-1540LE-MHQ, IDS Imaging Development Systems, Obersulm, Germany), and the Qualisperm Software (Biophos SA, Lausanne, Switzerland). To comply with the optimal functioning of the software algorithm, the extended semen was further extended with the same medium to a final 1:250 rate. Hens $(n=8)$ were mated and, $24 \mathrm{~h}$ later, euthanized by cervical dislocation and decapitation, along with unmated hens (controls, $n=4$ ). Both mated and control hens were maintained in the same husbandry conditions, following Swedish regulations, as previously described. Immediately post-mortem, the female oviduct was dissected out, and segments of the oviduct identified (UVJ, uterus, isthmus, magnum and infundibulum) under stereomicroscopy. Representative transversal samples were then collected at every segment, in its mid-region, following classical descriptions (Bakst 1998) and snapfrozen in liquid nitrogen $\left(\mathrm{LN}_{2}\right)$, prior to being stored at $-80^{\circ} \mathrm{C}$ until being processed. Collection instruments, gloves and specimen holders were changed between each specimen to avoid confounding contamination. A supplementary UVJ sample was obtained from each mated hen and fixed in $4 \%$ formaldehyde for histological confirmation of sperm presence in the SST-reservoirs.

\section{Ethics statement}

The experiments were approved well in advance by the 'Regional Committee for Ethical Approval of Animal Experiments' (Linköpings Djurförsöksetiska nämnd) in Linköping, Sweden (permit no 75-12).

\section{cDNA microarray}

A total of 36 microarrays were run for this experiment. In the case of UVJ-segments, four control females and eight 
mated females were used (12 arrays). In the case of the remaining oviductal segments (uterus, isthmus, magnum and infundibulum), three control and three mated females were used ( 24 arrays). Total RNA was extracted from the various samples using TRIzol (Invitrogen). Total RNA from each sample was quantified using a NanoDrop 1000 (Thermo Fisher Scientific, Fremont, CA, USA), with RNA integrity (RIN $\geq 8$ ) assessed using an Agilent 2100 Bioanalyzer (Agilent Technologies, Inc., Santa Clara, CA, USA). Double stranded cDNA was synthesized using RevertAid Premium First-Strand cDNA Synthesis Kit (Thermo Fisher Scientific) following the manufacturer's instructions. The ds-cDNA samples were cleaned, labeled, hybridized and washed according to the manufacturer's protocols of the Roche Nimblegen $12 \times 135 \mathrm{k}$ arrays, described elsewhere ( $\mathrm{Li}$ et al. 2013) and the manufacturers guidelines as detailed in the Gene Expression Analysis protocol (Roche NimbleGen Systems, Inc.). The cDNA microarray used customdesigned $12 \times 135 \mathrm{k}$ array slides for samples of UVJ, uterus, isthmus, magnum and infundibulum, derived from control (unmated) and mated birds. The array included all Ensembl (Flicek et al. 2012) and RefSeq (Pruitt et al. 2009) chicken transcripts. As well as all known transcripts, the array included probe sequences from a chicken brain cDNA library (Boardman et al. 2002), which provided a further 10686 probesets. Three 60-mer-oligonucleotide probes represented each transcript. To avoid SNPs in probe sequences, all known SNP position derived from the recent resequencing of Red Junglefowl and domestic chickens (Rubin et al. 2010) were masked, so that probes could not be chosen from sequences with known SNPs. This array design has been utilised extensively in previous work with the chicken strain utilised in this study (an advanced inter-cross between Red Junglefowl and White Leghorn birds). A targeted expression QTL analysis that utilised the comb tissue from 39 males (i.e. 39 arrays were used in the study) (Johnsson et al. 2014) was found to corroborate and develop the results previously obtained using qPCR (Johnsson et al. 2012). Furthermore, this same array design has been successfully used in a separate expression QTL study, this time involving the hypothalamus tissue of 129 advanced inter-cross individuals (Johnsson et al. 2015). Given these extensive studies using a variety of tissue types in the identical strain to that used in this study, and the custom nature of the design of this microarray, we have strong support for its reliability and the replication of results. The current microarray data are available in the ArrayExpress database (www. ebi.ac.uk/arrayexpress) (Kolesnikov et al. 2015) under the accession number E-MTAB-3327.

\section{Quantitative PCR assay}

The tissue samples used for the qPCR experiments were the same samples used for the microarray experiments.
Verification qPCRs were performed for four of the differentially expressed genes detected (for primer details see Supplementary Table 1, see section on supplementary data given at the end of this article) in the UVJ containing mucosal SST. First strand cDNA for qPCR was made with Fermentas (St Leon-Rot, Baden-Württemberg, Germany) RevertAid Reverse Transcriptase, using $10 \mathrm{mM}$ dNTPs, RiboLock nuclease inhibitor, and oligo $(\mathrm{dT})_{18}$ primer (Thermo Fisher Scientific), according to the manufacturer's protocol. qPCR was performed with Maxima SYBR Green qPCR mastermix (Thermo Fischer Scientific) in $15 \mu \mathrm{l}$ reactions with $0.3 \mathrm{M}$ of each oligonucleotide primer on a Rotor-Gene 6000 real-time cycler (Corbett Research, Cambridge, UK). The PCR program consisted of a $10 \mathrm{~min}$ activation step at $95^{\circ} \mathrm{C}$, followed by 40 cycles of $15 \mathrm{~s}$ at $95^{\circ} \mathrm{C}$, and $1 \mathrm{~min}$ at $60^{\circ} \mathrm{C}$. After cycling, products were melted by ramping the temperature from $72{ }^{\circ} \mathrm{C}$ to $95^{\circ} \mathrm{C}$. The qPCR data was analysed with the comparative $\Delta \Delta \mathrm{Ct}$ method (Livak \& Schmittgen 2001). The qPCR has been run in triplicate per gene per sample. Average $\mathrm{Ct}$ value of three housekeeping genes (reference genes)- $\beta 2$ microglobulin, TATA box binding protein, and RNA polymerase II subunit $\mathrm{C} 1$ - was subtracted from the average $\mathrm{Ct}$ value of target gene (control, mated) to calculate $\Delta \mathrm{Ct}$ of target gene. Normalized target gene expression in mated hens was calculated by a formula $2^{(-\Delta \Delta C t)}$.

\section{Statistical analysis}

Semen variables (sperm concentration and motility) are expressed as mean \pm s.E.M. Data were analysed using a non-parametric $t$-test (SPSS IBM corp. 2012 version 21). For the microarray, the slide was scanned following the protocol for scanning one-color NimbleGen arrays with the MS 200 Microarray Scanner and the MS 200 Data Collection Software. Scanned images (TIFF format) were then imported into DEVA Software (Roche NimbleGen, Inc, DEVA 1.2.1) for grid alignment and expression data analysis. Expression data were normalized through quantile normalization and the Robust Multichip Average (RMA) algorithm included in the Deva Software. Statistical analysis of normalized gene expression data was carried out using open source $\mathrm{R}$ (Version 3.1.2) software package. Dimensionality reduction was obtained through Principal Component Analysis (PCA) using package 'FactoMineR' and plotted using 'ggplot2' along the first two principal component capturing most of the variation in the data. Linear model using the empirical Bayes' approach as implemented in the package 'limma' was used to calculate differentially expressed genes in all oviductal segments between control $(n=3)$ and mated females $(n=3)$ except UVJ, where four controls and eight mated individuals were used. Multiple testing was carried out using False Discovery Rate (FDR) and 5\% FDR significance threshold (equivalent to a $P$ value of 0.05 ) was used to declare a significant difference (Adjusted $P$ value, $q$ ) between populations. 


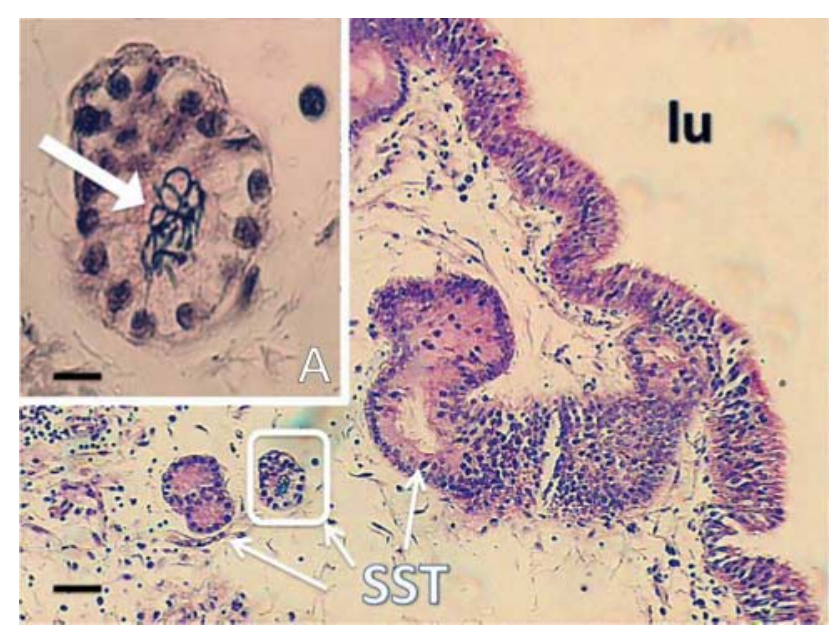

Figure 1 Representative histology of the UVJ containing mucosal SST holding the sperm. Microphotograph of a section of the UVJ of a mated hen (24 h post-mating) depicting sections of SST, Bar: $100 \mu \mathrm{m}, \mathrm{HE}$. In (A) a higher magnification (Bar: $10 \mu \mathrm{m}$ ) of a marked SST depicts spermatozoa in the lumen (thick arrow), Lu: lumen of the UVJ.

Gene ontological (GO) classification and functional analysis was carried out using an open source Panther Classification System (http://pantherdb.org) (Mi et al. 2013) and UniProtKB (http://www.uniprot.org/) (Magrane \& Uniprot 2011). The GO classified data were then exported into Microsoft Excel 2013 to produce pie chart figures for GO categories.

\section{Results}

The semen of the roosters used in the experiment varied in sperm concentration $(1.2 \pm 0.6-5.9 \pm 0.7 \mathrm{billion} / \mathrm{ml}$, mean \pm S.E.M.) and sperm progressive motility (74.4 \pm 15.8-99.00 $\pm 0.6 \%$ ), within ranges reported for RJF and commercial layers (Malik et al. 2013). All mated hens had spermatozoa in their SST, as representatively depicted in Fig. 1.

\section{Differential gene expression between mated and control individuals in the UVJ containing mucosal SST and uterus}

The cDNA microarray revealed differential gene expression in the UVJ containing mucosal SST and the uterus while the isthmus, magnum and infundibulum remained unchanged between control and mated individuals (Fig. 2). Analysis of the first and second components of the PCA (Fig. 2A, B, C, D and E) showed $50-65 \%$ of the total variation came from betweengroups despite volcano plots (Fig. 2F, G, H, I and J) indicating only the UVJ and the uterus showed a significant differential expression of certain genes. In total, 15 genes were differentially regulated between control and mated birds in the UVJ containing mucosal SST, and seven in the uterus (see Table 1).

\section{Classification of differentially expressed genes in UVJ containing mucosal SST and uterus in response to mating}

Differentially expressed genes (control vs mated) $(q \leq 0.05)$ have been classified for functionality based on both online database services and peer reviewed published articles (Table 2). The highest (eight) and second highest (three) number of differentially expressed genes in the UVJ containing mucosal SST were found
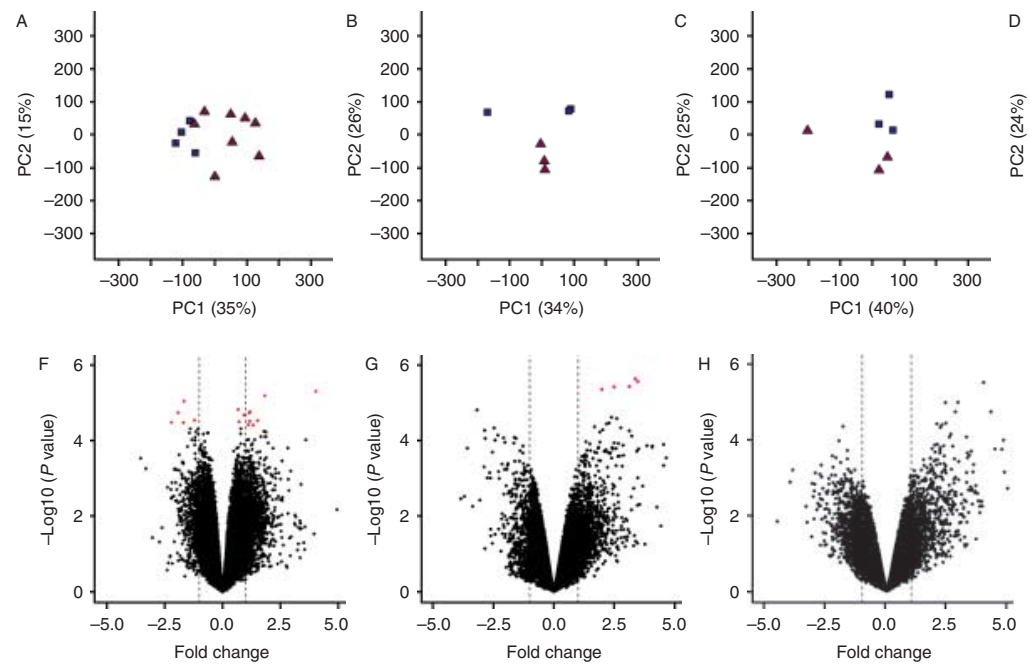
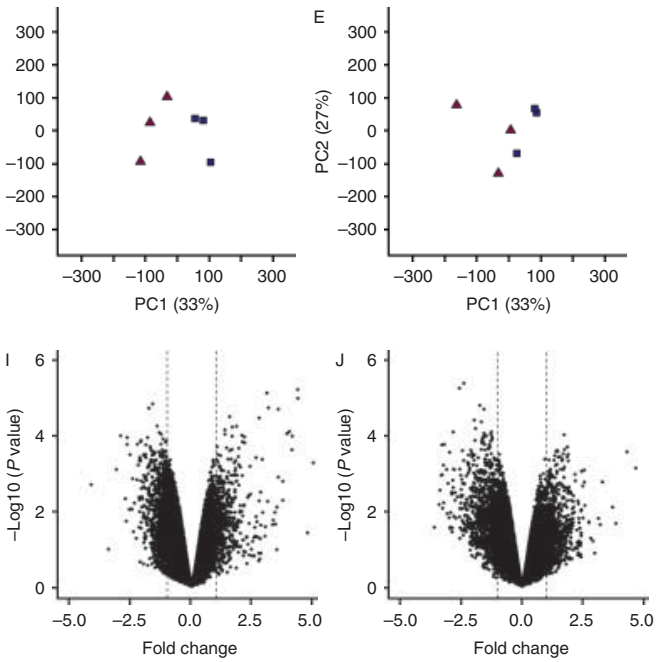

Figure 2 PCA and volcano plots for gene expressions in all oviductal segments (control vs mated individuals). First and second significant components (A, B, C, D and E) show 50, 60, 65, 57 and 60\% variation in UVJ, uterus, isthmus, magnum and infundibulum respectively. Volcano plots (F, G, H, I and J) show up- and down-regulated gene expressions in UVJ, uterus, isthmus, magnum and infundibulum. The $X$-axis represents fold change (FC) in gene expression and $Y$-axis represents $-\log 10$ of $P$ value. Vertical dashed lines represents logFC cut off values -1.00 or +1.00 and red dots represent differentially expressed genes $(q \leq 0.05)$. 
Table 1 Differentially expressed genes in the UVJ containing mucosal SST and the uterus of mated hens compared to unmated (control) hens at $5 \%$ FDR corrected $P$ value $(q \leq 0.05)$.

\begin{tabular}{|c|c|c|c|c|c|c|}
\hline Gene symbol or ID & Tissue & ENSEMBL/UniProtKB ID & Gene name & $\log \mathrm{FC}$ & $P$ value & $q$ value \\
\hline \multicolumn{7}{|l|}{ Up-regulated } \\
\hline LOC424944 & UVJ & ENSGALG00000008283/F1P1T3 & $\begin{array}{l}\text { Cytochrome P450 2J2-like } \\
\text { (LOC424944) }\end{array}$ & 4.04 & $4.90 \times 10^{-06}$ & 0.047 \\
\hline PLCH1 & UVJ & ENSGALG00000010312/E1C7E3 & Phoshpolipase C et al. & 1.82 & $6.46 \times 10^{-06}$ & 0.047 \\
\hline RHAG & UVJ & ENSGALG00000016684/F1NFG6 & Rh-associated glycoprotein & 1.52 & $2.94 \times 10^{-05}$ & 0.048 \\
\hline PLA2G2E & UVJ & ENSGALG00000014176/F1NZ96 & Phospholipase A2, group IIE & 1.19 & $1.73 \times 10^{-05}$ & 0.048 \\
\hline CPAMD8 & UVJ & ENSGALG00000003742/F1NN85 & $\begin{array}{l}\text { C3 and PZP-like, alpha-2-macro- } \\
\text { globulin domain containing } 8\end{array}$ & 1.17 & $3.05 \times 10^{-05}$ & 0.048 \\
\hline ATP13A3 & UVJ & ENSGALG00000007075/E1C7N6 & ATPase type $13 \mathrm{~A} 3$ & 1.15 & $1.84 \times 10^{-05}$ & 0.048 \\
\hline C17ORF85 & UVJ & ENSGALG00000002653/F1NGX2 & $\begin{array}{l}\text { Chromosome } 19 \text { open reading } \\
\text { frame, human C } 17 \text { orf } 85\end{array}$ & 1.11 & $3.78 \times 10^{-05}$ & 0.049 \\
\hline SLC12A8 & UVJ & ENSGALG00000012045/F1NG01 & Solute carrier family 12 , member 8 & 0.93 & $2.09 \times 10^{-05}$ & 0.048 \\
\hline LOC771318 & UVI & ENSGALG00000015516/F1NR26 & Phosphodiesterase 7A & 0.72 & $3.16 \times 10^{-05}$ & 0.048 \\
\hline LMBRD2 & UVJ & ENSGALG00000013377/E1BV17 & LMBR1 domain containing 2 & 0.67 & $1.49 \times 10^{-05}$ & 0.048 \\
\hline GKN2 & Uterus & ENSGALG00000000119/E1C2G7 & Gastrokine 2 & 8.40 & $1.71 \times 10^{-06}$ & 0.019 \\
\hline LOC395256 & Uterus & ENSGALG00000010927/F1NSM7 & $\begin{array}{l}\text { Matrix extracellular } \\
\text { phosphoglycoprotein }\end{array}$ & 7.79 & $9.04 \times 10^{-09}$ & 0.0001 \\
\hline IGFN1 & Uterus & ENSGALG00000000295/E1C7I7 & $\begin{array}{l}\text { Immunoglobulin-like and fibronec- } \\
\text { tin type III domain containing } 1\end{array}$ & 3.46 & $4.95 \times 10^{-06}$ & 0.024 \\
\hline Q7LZSO_CHICK & Uterus & ENSGALG00000008678/E1BX43 & Kininogen 1 & 3.36 & $4.21 \times 10^{-06}$ & 0.024 \\
\hline KCNV1 & Uterus & ENSGALG00000016109/E1BQJ2 & $\begin{array}{l}\text { Potassium channel, subfamily } \mathrm{V} \text {, } \\
\text { member } 1\end{array}$ & 3.12 & $6.63 \times 10^{-06}$ & 0.024 \\
\hline ADORA2A & Uterus & ENSGALG00000006642/E1BXP5 & Adenosine receptor A2 & 2.48 & $6.78 \times 10^{-06}$ & 0.024 \\
\hline QOKKP4_CHICK & Uterus & ENSGALG00000009365/F1P0L8 & $\begin{array}{l}\text { Cytochrome P450, family } 51, \\
\text { subfamily A, polypeptide } 1\end{array}$ & 1.98 & $7.79 \times 10^{-06}$ & 0.024 \\
\hline \multicolumn{7}{|l|}{ Down-regulated } \\
\hline RGS1 & UVJ & ENSGALG00000002549/E1BU64 & Regulator of G-protein signaling 1 & -2.20 & $3.27 \times 10^{-05}$ & 0.048 \\
\hline$G Z M A$ & UVJ & ENSGALG00000013548/F1 N917 & $\begin{array}{l}\text { Granzyme A (granzyme 1, cytotoxic } \\
\text { T-lymphocyte-associated serine } \\
\text { esterase } 3 \text { ) }\end{array}$ & -1.92 & $1.80 \times 10^{-05}$ & 0.048 \\
\hline LOC417962 & UVJ & ENSGALG00000011799/E1BQK1 & Uncharacterised (LOC4179620) & -1.68 & $3.32 \times 10^{-05}$ & 0.048 \\
\hline FGF18 & UVJ & ENSGALG00000002203/Q91950 & Fibroblast growth factor 18 & -1.59 & $7.43 \times 10^{-07}$ & 0.016 \\
\hline $\begin{array}{l}\text { ENSGALG } \\
00000013955\end{array}$ & UVJ & ENSGALG00000013955/1BW70 & Uncharacterised & -1.21 & $2.89 \times 10^{-05}$ & 0.048 \\
\hline
\end{tabular}

classified as immune regulatory (53.33\%) and $\mathrm{pH}$-regulatory $(20 \%)$ respectively. In the case of the uterus, there was no particular enrichment of any one category, though the number of differentially expressed genes was so small this is hardly surprising. Additional gene ontology (GO) analyses results of differentially expressed genes based on log fold change with a lower significance threshold (for up regulated genes, $\log \mathrm{FC}>0.45$ and for downregulated genes, $\log \mathrm{FC}<-0.45)$ are shown in Fig. 3 for the UVJ and Supplementary Figure 1, see section on supplementary data given at the end of this article for the remainder of the oviductal segments. Twelve categories were identified (see Fig. 3), with metabolic process (GO: 0008152) consistently being the largest GO category identified in each sample tissue. However, the immune system process (GO: 0002376) and response to stimulus (GO: 0050896) categories were also identified (Fig. 3). The immune system process is directly related to sperm survival and it was therefore considered to be of prime interest for further investigation. The GO term 'response to stimulus' was also considered important for further investigation, because gene shifts in this category might be due to the stimuli produced by the post-mating spermatozoa in the UVJ (Fig. 1). A total of 122 up-regulated and 103 downregulated genes in the UVJ of mated hens were categorized as being related to the immune system process (Supplementary Table 2). Similarly, 109 up-regulated and 99 down-regulated genes were found in the GO term category 'response to stimulus' (Supplementary Table 3). The possible roles of these up- and downregulated genes in the UVJ have been summarized in Supplementary Tables 2 and 3.

\section{Differential gene expression by oviductal segments}

A comparison of expression between oviductal segments for down- and up-regulated genes is presented in Table 3. Irrespective of mating, the UVJ containing mucosal SST possessed the greatest number of downregulated genes, as compared to the other segments. The UVJ, uterus and magnum had greater numbers of up-regulated genes. In terms of the number of unique (specific to a single segment) genes that were suggestively differentially expressed (logFC $>0.45$ or logFC $<-0.45)$ in the UVJ, we found a total of 1712 genes 
Table 2 Functional classification of differentially expressed (control vs mated) genes at $5 \%$ FDR corrected $P$ value $(q \leq 0.05)$ in the UVJ containing mucosal SST and uterus of hens.

\begin{tabular}{|c|c|c|c|}
\hline Category & Gene symbols & $\begin{array}{l}\text { Number of } \\
\text { genes }(\%)\end{array}$ & Tissue \\
\hline Immune-modulatory & $\begin{array}{c}\text { LMBRD2, CPAMD8, } \\
\text { P450, PLA2G2E, } \\
\text { RGS1, PDE7A, } \\
\text { GZMA, PLCH1 }\end{array}$ & $8(53.33)$ & UVJ \\
\hline pH-regulatory & $\begin{array}{l}\text { ATP13A3, SLC12A8, } \\
\text { RHAG }\end{array}$ & $3(20)$ & UVJ \\
\hline Growth factor & FGF18 & $1(6.67)$ & UVJ \\
\hline Uncharacterized & $\begin{array}{l}\text { C17orf85, } \\
\text { LOC417962, } \\
\text { ENSGAL- } \\
\text { G00000013955 }\end{array}$ & $3(20)$ & UVJ \\
\hline Receptor activity & ADORA2A & $1(14.29)$ & Uterus \\
\hline $\begin{array}{l}\text { Structural molecule } \\
\text { activity }\end{array}$ & IGFN1 & $1(14.29)$ & Uterus \\
\hline Transporter activity & KCNV1 & $1(14.29)$ & Uterus \\
\hline $\begin{array}{l}\text { Egg shell formation } \\
\text { related }\end{array}$ & $\begin{array}{l}\text { Ovocleidin 116, } \\
\text { GKN2 }\end{array}$ & $2(28.51)$ & Uterus \\
\hline Unknown & $\begin{array}{l}\text { KNG1, } \\
\text { Q0KKP4_CHICK }\end{array}$ & $2(28.51)$ & Uterus \\
\hline
\end{tabular}

were up-regulated and 977 genes were down-regulated (see Supplementary Excel file 1, see section on supplementary data given at the end of this article, where the further gene ontology analysis results of these genes can be seen).

\section{Four differentially expressed genes in the UVJ were validated by $q P C R$}

The two up-regulated $(\operatorname{logFC}>0.45)$ genes $(\mathrm{P} 450$ and PTGS1) and the two down-regulated (logFC $<-0.45)$ genes (RGS1 and GZMA) revealed by microarray analysis were also expressed in the same direction when measured by real time quantitative polymerase chain reaction (Fig. 4), to verify the microarray results (see also methods section for further confirmation analysis).

\section{Discussion}

The present study reveals that sperm deposition during natural mating causes relatively rapid (within $24 \mathrm{~h}$ ) changes in the expression of genes involved in immune-modulatory and $\mathrm{pH}$-regulatory functions, both relevant for sperm survival in the reproductive tract of hens. However, these changes are apparent only in the UVJ containing mucosal SSTs and the uterus. Absence of such significant gene expression shifts in other areas, indicates that the UVJ function requires up- or downregulation of specific genes within a brief period postentry, to warrant the storage of sufficient fertile spermatozoa for fertilization in the primary sperm reservoir (mucosal SSTs).
The examination of the UVJ revealed that both immune-reactive and immune-suppressive genes were differentially expressed in mated hens. The immunemodulatory genes found in the current study have also been related to immune regulation by other studies. For instance LMBRD2- is responsible for cellular migration in Dictyostelium dicoideum (Kelsey et al. 2012); GZMA - is able to produce local inflammatory response in the target cells (Irmler et al. 1995, Catalfamo \& Henkart 2003, Bots \& Medema 2006); PDE7A is expressed in human T cells (Mary et al. 1987, Krause \& Deutsch 1991, Soderling \& Beavo 2000); RGS1 is a regulator of G protein-couple receptors (GPCR) (see review Cho \& Kehrl (2009)); $\mathrm{PLCH} 1$ is responsible for GPCR mediated signaling in mouse neuroblastoma cells Neuro2A (N2A) cells (Kim et al. 2011) and CPAMD8 in human is also related to immune-regulation (Philip et al. 1994, Volanakis 2002, Skornicka et al. 2004, Athippozhy et al. 2011, Jeng et al. 2011). Moreover, the up-regulation of P450 and PTGS1 in the UVJ of mated hens could potentially indicate the synthesis of prostaglandin in this area. PTGS-derived prostaglandins are involved both in oviductal motility (Brillard 1993) as well as in immune-modulation (Harris et al. 2002, Nebert \& Dalton 2006). Following reports that spermatozoa could stimulate prostaglandin synthesis in bovine oviductal cells (Kodithuwakku et al. 2007), we hereby speculate that the entry of spermatozoa and the over-expression of PLA2G2E in the UVJ-area might enhance the up-regulation of PTGS1 and prostaglandin synthesis (Murakami et al. 2002). Interestingly, the gene P450 has been indicated as being differentially expressed in Drosophila melanogaster females in response to mating (McGraw et al. 2004).

One could argue that male courtship and sexual harassment of the females, or even mating could have influenced the females and their oviducts, rather than or concerted with - the presence of sperm or seminal fluid. Hormonal and gene induction changes at brain level are elicited by these events (Ball \& Balthazart 2001) but evidence of changes at the oviduct level is yet, to the best of our knowledge, not available. Use of artificial insemination could provide some cues, by waiving this eventual male courtship/mating factor.

Spermatozoa are sensitive to $\mathrm{pH}$ and their motility is rapidly affected by changes in $\mathrm{pH}$ levels. In domestic mammals (cow and pigs) and avian (chicken, quail and turkey) in vitro sperm motility is highest at an alkaline $\mathrm{pH}$ and can be manipulated towards quiescence by exposure to low pH (Holm \& Wishart 1998, RodriguezMartinez 2007). In chicken, pH values below 7.8 inhibit sperm motility, and at this level sperm motility remains low, while raising the $\mathrm{pH}$ value 0.2 units and higher provides vigorous sperm motility (Holm \& Wishart 1998). In vivo, porcine spermatozoa are quiescent in the cauda epididymides $(\mathrm{pH}$ 6.5, Rodriguez-Martinez et al. 1990); motility becoming activated by exposure to high $\mathrm{pH}$ or increasing bicarbonate levels 
A UVJ: biological process, logFC $>0.45$ (control vs mated)

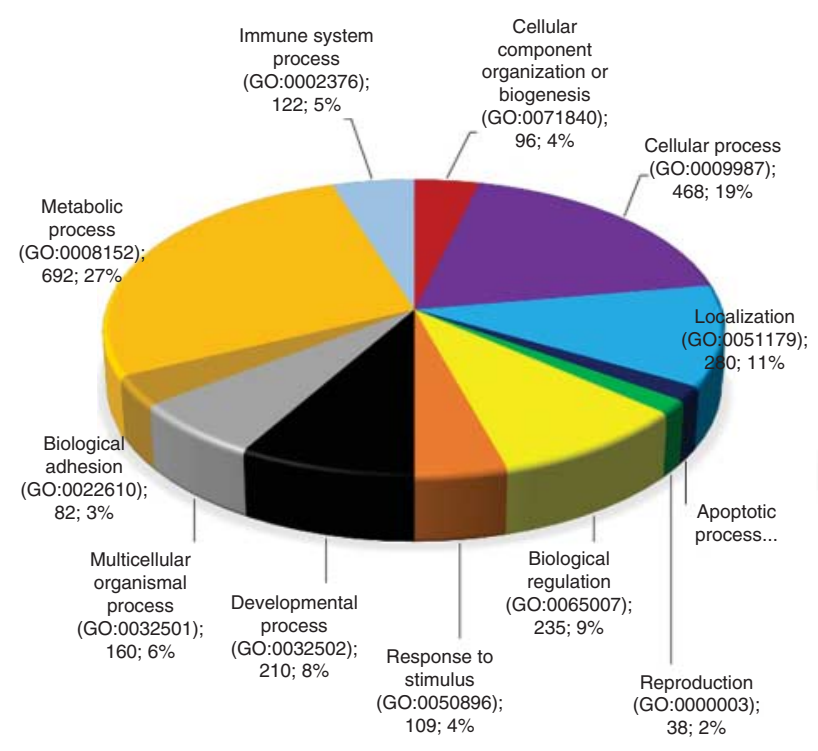

C UVJ: response to stimulus, logFC $>0.45$ (control vs mated)

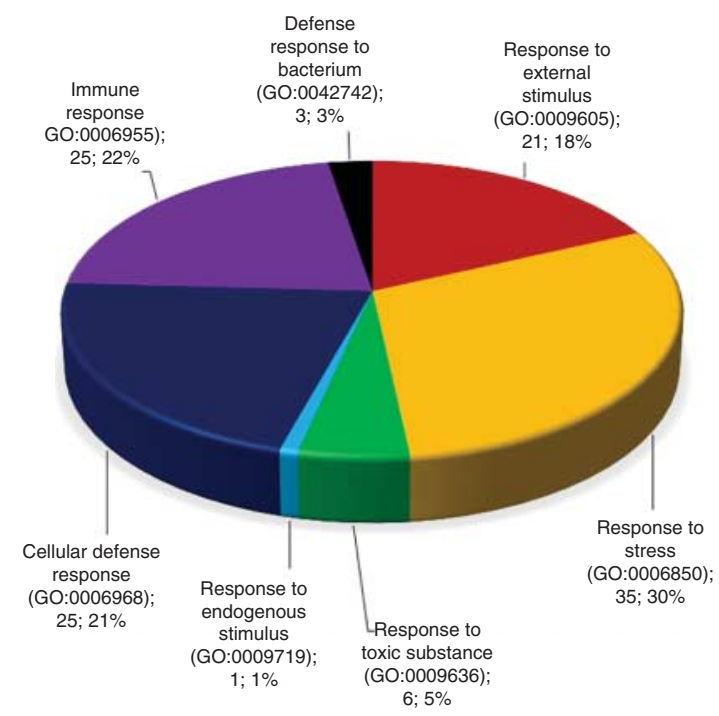

B UVJ: biological process, logFC $<-0.45$ (control vs mated)

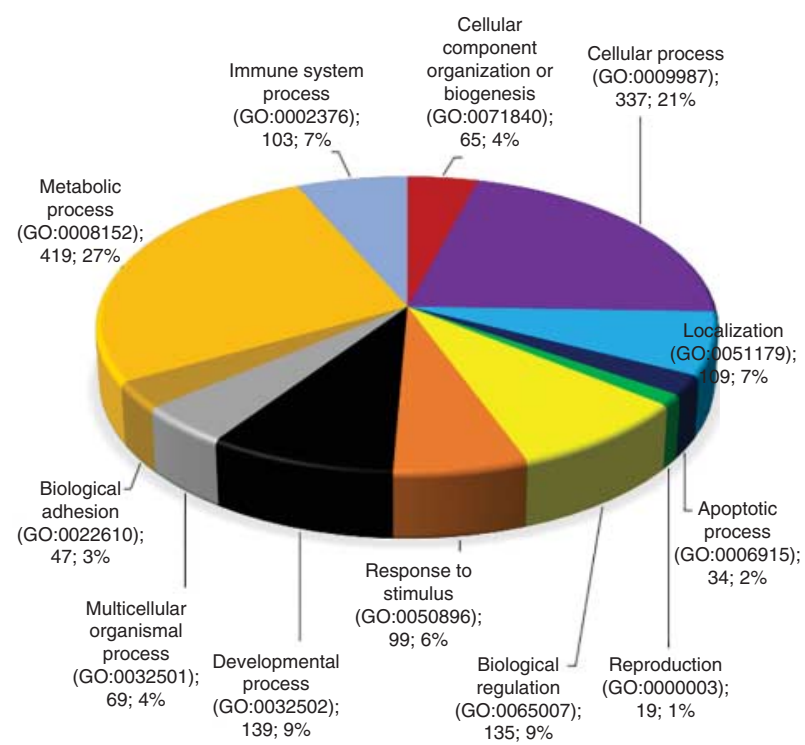

D UVJ: response to stimulus, $\log \mathrm{FC}<-0.45$ (control vs mated)

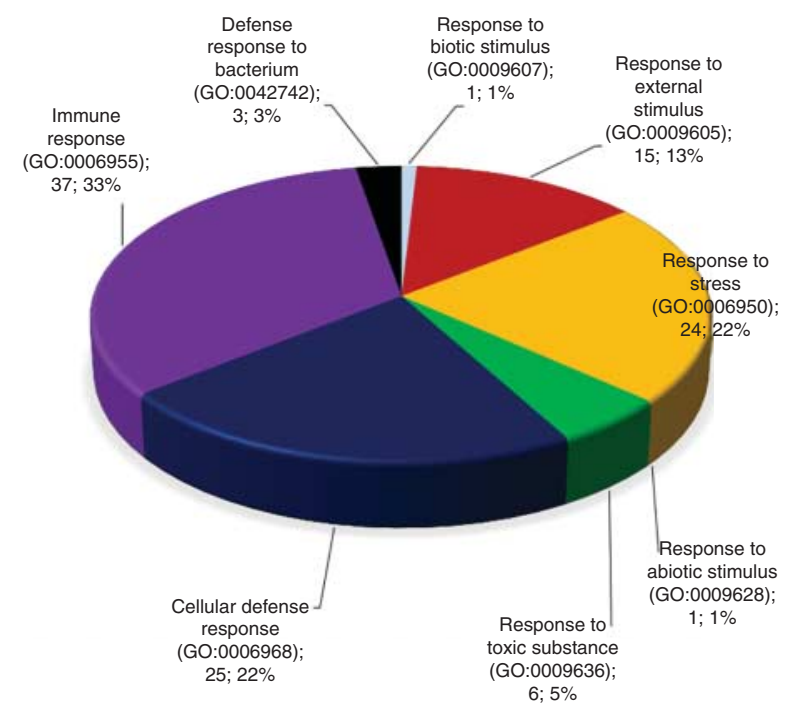

Figure 3 Gene ontology (GO) analysis of differentially expressed (logFC either $>0.45$ or $<-0.45$ ) genes in UVJ (control vs mated individuals). Data label represents category name (Accession), number of genes and percent of gene hit against total number of biological process hits. (A) Total number of genes $(n)=1539$; total number of biological process hits $(N)=2532$. (B) $n=1120 ; N=1575$. (C) $n=109 ; N=116$. (D) $n=99 ; N=112$.

(Rodriguez-Martinez 2007). Interestingly, the oviductal sperm reservoirs of the sow register lower $\mathrm{pH}$ levels (6.7) compared to the upper tubal segments where fertilization takes place (ampullary-isthmic junction: 7.5; ampullae: 8.3) (Rodriguez-Martinez 2007) adding circumstantial evidence to suggestions that changes in $\mathrm{pH}$ from acidic to alkaline would also regulate sperm transfer to the fertilization site (Holm et al. 1996). Interestingly, our current results indicate that the entry of spermatozoa to the SST at UVJ causes alterations in the expression of pH-regulatory genes such as ATP13A3,
SLC12A8, and RHAG. ATP13A3 potentially regulates $\mathrm{pH}$ by ion $\left(\mathrm{Na}^{+}\right.$or $\left.\mathrm{K}^{+}\right)$and proton $\left(\mathrm{H}^{+}\right)$exchange between intra and extracellular spaces (Pang et al. 2001, 2004, Bublitz et al. 2011, Palmgren \& Nissen 2011). Similarly, SLC12A8 also affects ion exchange (Arroyo et al. 2013), whilst RHAG functions in the exchange of protons between intra and extracellular spaces (Westhoff et al. 2004, Benjelloun et al. 2005). Therefore, it is possible that variation in $\mathrm{pH}$ is related to sperm quiescence during storage in the SST. Further studies are obviously needed to explore $\mathrm{pH}$ in the SST. 
Table 3 Inter-segmental differential gene expressions in control and mated hens.

\begin{tabular}{|c|c|c|c|c|c|c|}
\hline & & \multicolumn{5}{|c|}{ Total downregulated genes } \\
\hline & & Infundibulum & Magnum & Isthmus & Uterus & UVJ \\
\hline \multirow[t]{2}{*}{ Infundibulum } & Control & & 2586 & 1255 & 1399 & 4630 \\
\hline & Mated & & 3281 & 714 & 951 & 1381 \\
\hline \multirow[t]{2}{*}{ Magnum } & Control & 2328 & & 875 & 1195 & 4592 \\
\hline & Mated & 2588 & & 456 & 1361 & 3152 \\
\hline \multirow[t]{2}{*}{ Isthmus } & Control & 8351 & 7391 & & 596 & 7313 \\
\hline & Mated & 5409 & 5827 & & 1309 & 5117 \\
\hline \multirow[t]{2}{*}{ Uterus } & Control & 7649 & 6806 & 308 & & 5945 \\
\hline & Mated & 7177 & 8733 & 1100 & & 5084 \\
\hline \multirow[t]{2}{*}{ UVJ } & Control & 7902 & 7389 & 2868 & 2653 & \\
\hline & Mated & 5694 & 7523 & 2564 & 1814 & \\
\hline
\end{tabular}

Total upregulated genes

The unique nature of the UVJ containing mucosal SST is also revealed by the large gene expression shifts that are unique to this segment at all times (irrespective of whether mating has taken place or otherwise). The UVJ had the greatest number of down-regulated genes relative to the other segments of the oviduct in the control birds, potentially preparing the area for the presence of foreign spermatozoa. Post insemination, the UVJ showed once again the greatest number of downregulated genes relative to the other oviductal segments (Table 3). Spermatozoa are retained in the SST for a longer duration than in any of the other compartments due to the nature of avian reproduction, making this compartment essential for sperm survival. Gene ontology (GO) analysis of the differentially expressed genes in the UVJ showed an enrichment of 12 gene classes, among them several involved in the orchestration of immune-regulation (GO: 0002376: immune system; GO: 0050896: the response to stimulus) (Fig. 3A and B). Up to 122 up-regulated and 103 down-regulated genes were involved in immune system processes. Interestingly, most of the down-regulated genes in the immune system process category belong to the immune reactive functions while up-regulated genes in this category belong to immune reactive, immune suppressive and other functions (see Supplementary Table 2, see section on supplementary data given at the end of this article). The presence of spermatozoa in the SST at UVJ confirmed that this compartment was colonized in mated females. GO analysis revealed the majority of the down-regulated genes in the GO term category 'response to stimulus' are immune responsive while the majority of the up-regulated genes are related to stress responsiveness (Fig. 3C and D). The data indicate that immune responsive genes are down regulated in the UVJ of mated hens, which might favor the survival of spermatozoa in its mucosal SSTs.

Of the seven genes up-regulated in the uterus of mated hens, Ovocleidin 116 is a candidate molecule for the regulation of calcite growth during egg shell calcification (Hincke et al. 1999). GKN2 is an eggshell specific protein (Jonchère et al. 2010) while the function of KNG1 is yet unknown. IGFN1 is responsive to stress and elasticity (Erickson 1994, Mansilla et al. 2008). KCNV1 is a voltage-dependent $\mathrm{K}^{+}$exchanger (González et al. 2012). ADORA2A is a G-protein-coupled receptor partly responsible for the immune modulatory pathway (Haskó et al. 2000). Cyp51A1, which is a member of cytochrome P450 family, is responsible for prostaglandin synthesis (Nebert \& Dalton 2006), and appears to help in the survival of pre-fertilized spermatozoa as well as aids in egg shell formation and increasing elasticity in the uterus (Table 2). The Ovocleidin 116 and GKN2 are also reported to be up-regulated in the uterus of laying hens when compared to juvenile hens (Dunn et al. 2009).

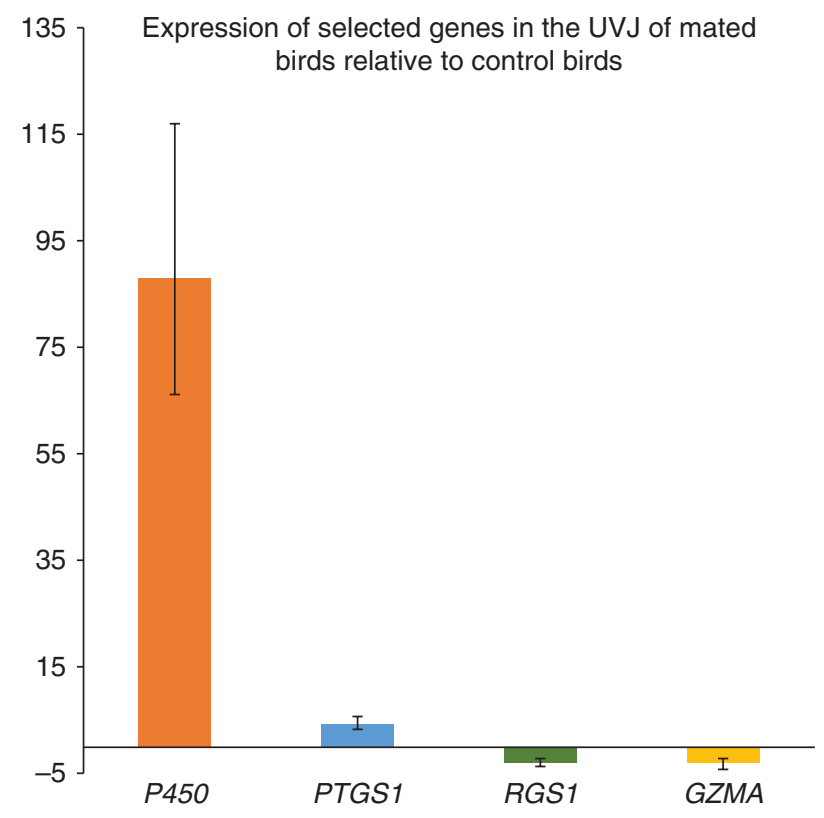

Figure 4 Quantitative PCR verification of microarray results. Two up-regulated (logFC $>0.45)$ genes- P450, PTGS1 and two downregulated (logFC $<-0.45)$ genes- RGS1, GZMA have been verified using GPCR assay. The $Y$-axis represents mean expression (calculated by $2^{-\Delta \Delta \mathrm{Ct}}$ ) of genes and the error bars represents \pm S.E.M. 
Summarizing all the differentially expressed genes, we can speculate that changes in the expression of genes in the UVJ containing mucosal SST of mated hens might participate in immune-modulation and the regulation of $\mathrm{pH}$ in the segment. Changes in the expression of genes in the uterus might be involved in egg shell formation and immune-modulation while gene expression shift in other segments of the oviduct remained non-significant between control and mated hens. Such immunemodulatory and $\mathrm{pH}$-regulatory gene shifts in the UVJ could promote sperm survival by immune-suppression while immune-reactivity might eliminate dead spermatozoa or sperm/seminal fluid debris. Similarly, changes in local pH might keep spermatozoa quiescent or increase their motility depending on whether they will be retained in the SST or released from this compartment for fertilization. However, further research is required to explore the roles of each of the differentially expressed genes regarding cross-talk between spermatozoa and the oviduct of mated chicken.

\section{Supplementary data}

This is linked to the online version of the paper at http://dx.doi. org/10.1530/REP-15-0253.

\section{Declaration of interest}

The authors declare that there is no conflict of interest that could be perceived as prejudicing the impartiality of the research reported.

\section{Funding}

The project has been financed by the Research Council FORMAS, Stockholm. (Project number: 221-2011-512). Funding for D Wright and J Fogelholm was from the FORMAS grant number: 221-2012-667 and VR grant number: 621-2011-4802.

\section{Acknowledgements}

We are grateful to Martin Johnsson and Andrey Höglund (IFM Biology, LiU), who helped with the cDNA microarray analysis and qPCR assay. We would also like to thank Prof Per Jensen for the generous use of the chickens in this study.

\section{References}

Abdel-Mageed AM, Isobe N \& Yoshimura Y 2008 Expression of avian $\beta$-defensins in the oviduct and effects of lipopolysaccharide on their expression in the vagina of hens. Poultry Science 87 979-984. (doi:10.3382/ps.2007-00283)

Arroyo JP, Kahle KT \& Gamba G 2013 The SLC12 family of electroneutral cation-coupled chloride cotransporters. Molecular Aspects of Medicine 34 288-298. (doi:10.1016/j.mam.2012.05.002)

Athippozhy A, Huang L, Wooton-Kee CR, Zhao T, Jungsuwadee P, Stromberg AJ \& Vore M 2011 Differential gene expression in liver and small intestine from lactating rats compared to age-matched virgin controls detects increased mRNA of cholesterol biosynthetic genes. BMC Genomics 12 95-111. (doi:10.1186/1471-2164-12-95)

Bakst MR 1998 Structure of the avian oviduct with emphasis on sperm storage in poultry. Journal of Experimental Zoology 282 618-626. (doi:10.1002/(SICI)1097-010X(199811/12)282:4/5 <618::AID-JEZ11> 3.0.CO;2-M)

Bakst MR 2011 Role of the oviduct in maintaining sustained fertility in hens. Journal of Animal Science 89 1323-1329. (doi:10.2527/ jas.2010-3663)

Ball GF \& Balthazart J 2001 Ethological concepts revisited: immediate early gene induction in response to sexual stimuli in birds. Brain, Behavior and Evolution 57 252-270. (doi:10.1159/000047244)

Benjelloun F, Bakouh N, Fritsch J, Hulin P, Lipecka J, Edelman A, Planelles G, Thomas SR \& Chérif-Zahar B 2005 Expression of the human erythroid Rh glycoprotein (RhAG) enhances both $\mathrm{NH}_{3}$ and $\mathrm{NH}_{4}+$ transport in HeLa cells. European Journal of Physiology 450 155-167. (doi:10.1007/s00424-005-1381-y)

Boardman PE, Sanz-Ezquerro J, Overton IM, Burt DW, Bosch E, Fong WT, Tickle C, Brown WRA, Wilson SA \& Hubbard SJ 2002 A comprehensive collection of chicken cDNAs. Current Biology 12 1965-1969. (doi:10.1016/S0960-9822(02)01296-4)

Bots M \& Medema JP 2006 Granzymes at a glance. Journal of Cell Science 119 5011-5014. (doi:10.1242/jcs.03239)

Brillard JP 1993 Sperm storage and transport following natural mating and artificial insemination. Poultry Science 72 923-928. (doi:10.3382/ps. 0720923)

Bublitz M, Preben M \& Nissen P 2011 P-type ATPases at a glance. Journal of Cell Science 124 2515-2519. (doi:10.1242/jcs.088716)

Catalfamo M \& Henkart PA 2003 Perforin and the granule exocytosis cytotoxicity pathway. Current Opinion in Immunology 15 522-527. (doi:10.1016/S0952-7915(03)00114-6)

Cho H \& Kehrl JH 2009 Regulation of immune function by G proteincoupled receptors, trimeric G proteins, and RGS proteins. Progress in Molecular Biology and Translational Science 86 249-298. (doi:10.1016/ S1877-1173(09)86009-2)

Das SC, Isobe N, Nishibori M \& Yoshimura Y 2006 Expression of transforming growth factor- $\beta$ isoforms and their receptors in uterovaginal junction of hen oviduct in presence or absence of resident sperm with reference to sperm storage. Reproduction 132 781-790. (doi:10.1530/rep.1.01177)

Das SC, Isobe N \& Yoshimura Y 2008 Mechanisms of prolonged sperm storage and sperm suvivality in hen oviduct: a review. American Journal of Reproductive Immunology 60 477-481. (doi:10.1111/ j.1600-0897.2008.00651.x)

Das SC, Isobe N \& Yoshimura Y 2009 Changes in the expression of interleukin-1 $\beta$ and lipopolysaccharide-induced TNF factor in the oviduct of laying hens in response to artificial insemination. Reproduction 137 527-536. (doi:10.1530/REP-08-0175)

Dunn IC, Wilson PW, Lu Z, Bain MM, Crossan CL, Talbot RT \& Waddington D 2009 New hypotheses on the function of the avian shell gland derived from microarray analysis comparing tissue from juvenile and sexually mature hens. General and Comparative Endocrinology 163 225-232. (doi:10.1016/j.ygcen.2009.03.006)

Erickson HP 1994 Reversible unfolding of fibronectin type III and immunoglobulin domains provides the structural basis for stretch and elasticity of titin and fibronectin. PNAS 91 10114-10118. (doi:10.1073/ pnas.91.21.10114)

Fazeli A, Affara NA, Hubank M \& Holt WV 2004 Sperm-induced modification of the oviductal gene expression profile after natural insemination in mice. Biology of Reproduction 71 60-65. (doi:10.1095/ biolreprod.103.026815)

Flicek P, Amode MR, Barrell D, Beal K, Brent S, Carvalho-Silva D, Clapham P, Coates G, Fairley S, Fitzgerald S et al. 2012 Ensembl. Nucleic Acids Research 40 D84-D90. (doi:10.1093/nar/gkr991)

Georgiou AS, Snijders APL, Sostaric E, Aflatoonian R, Vazquez JL, Vazquez JM, Roca J, Martinez EA, Wright PC \& Fazeli A 2007 Modulation of the oviductal environment by gametes. Journal of Proteome Research 6 4656-4666. (doi:10.1021/pr070349m)

González C, Baez-Nieto D, Valencia I, Oyarzún I, Rojas P, Naranjo D \& Latorre R $2012 \mathrm{~K}^{+}$channels: function-structural overview. Comprehensive Physiology 2 2087-2149. (doi:10.1002/cphy.c110047) 
Harris SG, Padilla J, Koumas L, Ray D \& Phipps RP 2002 Prostaglandins as modulators of immunity. Trends in Immunology 23 144-150. (doi:10.1016/S1471-4906(01)02154-8)

Haskó G, Kuhel DG, Chen J-F, Schwarzscgild MA, Deitch EA, Mabley JG, Marton A \& Szabó C 2000 Adenosine inhibits IL-12 and TNF- $\alpha$ production via adenosine $\mathrm{A} 2 \mathrm{a}$ receptor-dependent and independent mechanisms. FASEB Journal 14 2065-2074. (doi:10.1096/fj.99-0 508com)

Hincke MT, Gautron J, Tsang CPW, McKee MD \& Nys Y 1999 Molecular cloning and ultrastructural localization of the core protein of an eggshell matrix proteoglycan, ovocleidin-116. Journal of Biological Chemistry 274 32915-32923. (doi:10.1074/jbc.274.46.32915)

Holm L \& Wishart GJ 1998 The effect of pH on the motility of spermatozoa from chicken, turkey and quail. Animal Reproduction Science 54 45-54. (doi:10.1016/S0378-4320(98)00142-0)

Holm L, Ridderstråle Y \& Knutsson P-G 1996 Localization of carbonic anhydrase in the sperm storing regions of the domestic hen oviduct. Acta Anatomica 156 253-260. (doi:10.1159/000147853)

Huang H-L, Cheng Y-S, Yang K-T, Chen C-H, Huang M-C \& Hsu W-H 2011 Genome-wide transcript expression analysis in the uterovaginal junction in association with fertile period in Tsaiya Ducks. Journal of Reproduction and Development 57 731-736. (doi:10.1262/jrd.11-032K)

Irmler M, Hertig S, MacDonald HR, Sadoul R, Becherer JD, Proudfoot A, Solari R \& Tschopp J 1995 Granzyme A is an interleukin $1 \beta$-converting enzyme. Journal of Experimental Medicine 181 1917-1922. (doi:10.1084/jem.181.5.1917)

Ito T, Yoshizaki N, Tokumoto T, Ono H, Yoshimura T, Tsukada A, Kansaku N \& Sasanami T 2011 Progesterone is a sperm-releasing factor from the sperm-storage tubules in birds. Endocrinology 152 3952-3962. (doi:10.1210/en.2011-0237)

Jeng D, Rahman MM, McFadden G \& Essani K 2011 Tumor necrosis factor inhibitors from poxviruses with emphasis on tanapoxvirus-2L protein. Recent Patents on DNA \& Gene Sequences 5 97-103. (doi:10.2174/ 187221511796392033)

Johnsson M, Jonsson KB, Andersson L, Jensen P \& Wright D 2015 Genetical Genomics of Behavior: A novel chicken genomic model for anxiety behavior. Genetics. In press.

Johnsson M, Gustafson I, Rubin C-J, Sahlqvist A-S, Johnsson KB, Kerje S, Ekwall O, Käampe O, Andersson L, Jensen P et al. 2012 A sexual ornament in chickens is affected by pleiotropic alleles at HAO1 and BMP2, selected during domestication. PLoS Genetics 8 e1002914. (doi:10.1371/journal.pgen.1002914)

Johnsson M, Rubin CJ, Höglund A, Sahlqvist AS, Jonsson KB, Kerje S, Ekwall O, Kämpe O, Andersson L, Jensen P et al. 2014 The role of pleiotropy and linkage in genes affecting a sexual ornament and bone allocation in the chicken. Molecular Ecology 23 2275-2286. (doi:10.1111/mec.12723)

Jonchère V, Rèhault-Godbert $S$, Hennequet-Antier C, Cabau C, Sibut V, Cogburn LA, Nys Y \& Gautron J 2010 Gene expression profiling to identify eggshell proteins involved in physical defense of the chicken egg. BMC Genomics 11 57. (doi:10.1186/1471-2164-11-57)

Kelsey JS, Fastman NM \& Blumberg DD 2012 Evidence of an evolutionarily conserved LMBR1 domain-containing protein that associates with endocytic cups and plays a role in cell migration in Dictyostelium discoideum. Eukaryotic Cell 11 401-416. (doi:10.1128/ EC.05186-11)

Kim JK, Choi JW, Lim S, Kwon O, Seo JK, Ryu SH \& Suh P-G 2011 Phospholipase $\mathrm{C}-\eta 1$ is activated by intracellular $\mathrm{Ca}^{2+}$ mobilization and enhances GPCRs/PLC/Ca ${ }^{2+}$ signaling. Cellular Signalling 23 1022-1029. (doi:10.1016/j.cellsig.2011.01.017)

Kodithuwakku SP, Miyamoto A \& Wijayagunawardane MPB 2007 Spermatozoa stimulate prostaglandin synthesis and secretion in bovine oviductal epithelial cells. Reproduction 133 1087-1094. (doi:10.1530/ REP-06-0201)

Kolesnikov N, Hastings E, Keays M, Melenichuk O, Tang YA, Williams E, Dylag M, Kurbatova N, Brandizi M, Burdett T et al. 2015 ArrayExpress update-simplifying data submissions. Nucleic Acids Research 43 D113-D116. (doi:10.1093/nar/gku1057)

Krause DS \& Deutsch C 1991 Cyclic AMP directly inhibits IL-2 receptor expression in human T-cells. Expression of both p55 and p75 subunits is affected. Journal of Immunology 146 2285-2296.
Li J-P, Liu L-H, Li J, Chen Y, Jiang X-W, Ouyang Y-R, Liu Y-Q, Zhong H, Li H \& Xiao T 2013 Microarray expression profile of long noncoding RNAs in human osteosarcoma. Biochemical and Biophysical Research Communication 433 200-206. (doi:10.1016/j.bbrc.2013. 02.083)

Livak J \& Schmittgen T 2001 Analysis of relative gene expression data using real-time quantitativ PCR and the $2^{-\Delta \Delta C T}$ method. Methods $25402-408$. (doi:10.1006/meth.2001.1262)

Long EL, Sonstegard TS, Long JA, Van Tassell CP \& Zuelke A 2003 Serial analysis of gene expression in turkey sperm storage tubules in the presence and absence of resident sperm. Biology of Reproduction 69 469-474. (doi:10.1095/biolreprod.102.015172)

Magrane M \& Uniprot C 2011 UniProt Knowledgebase: a hub of integrated protein data. Database 2011 Bar009. (doi:10.1093/database/ bar009)

Malik A, Haron AW, Yusoff R, Nesa M, Bukar M \& Kasim A 2013 Evaluation of the ejaculate quality of the red jungle fowl, domestic chicken, and bantam chicken in Malaysia. Turkish Journal of Veterinary and Animal Sciences 37 564-568. (doi:10.3906/vet-1107-26)

Mansilla F, Dominguez CAG, Yeadon JE, Corydon TJ, Burden SJ \& Knudsen CR 2008 Translation elongation factor eEEF1A binds to a novel myosin binding protein-C-like protein. Journal of Cellular Biochemistry 105 847-858. (doi:10.1002/jcb.21880)

Mary D, Aussel C, Ferrua B \& Fehlmann M 1987 Regulation of interleukin 2 synthesis by CAMP in human T cells. Journal of Immunology 139 $1179-1184$.

McGraw LA, Gibson G, Clark AG \& Wolfner F 2004 Genes regulated by mating, sperm, or seminal proteins in mated female Drosophila melanogaster. Current Biology 14 1509-1514. (doi:10.1016/j.cub. 2004.08.028)

Mi H, Muruganujan A \& Thomas PD 2013 Panther in 2013: modeling the evolution of gene function, and other gene attributes, in the context of phylogenetic trees. Nucleic Acids Research 41 D377-D386. (doi:10.1093/nar/gks1118)

Murakami M, Yoshihara K, Shimbara S, Lambeau G, Singer A, Gelb MH, Sawada M, Inagaki N, Nagai H \& Kudo I 2002 Arachidonate release and eicosanoid generation by group IIE phospholipase $\mathrm{A}_{2}$. Biochemical and Biophysical Research Communication 292 689-696. (doi:10.1006/bbrc. 2002.6716)

Nebert DW \& Dalton TP 2006 The role of cytochrome P450 enzymes in endogenous signaling pathways and environmental carcinogenesis. Nature Reviews. Cancer 6 947-960. (doi:10.1038/nrc2015)

Palmgren MG \& Nissen P 2011 P-type ATPases. Annual Review of Biophysics 40 243-266. (doi:10.1146/annurev.biophys.093008. 131331)

Pang T, Su X, Wakabayashi S \& Shigekawa M 2001 Calcineurin homologous protein as an essential cofactor for $\mathrm{Na}^{+} / \mathrm{H}^{+}$exchange. Journal of Biological Chemistry 276 17367-17372. (doi:10.1074/jbc. M100296200)

Pang T, Hisamitsu T, Mori H, Shigekawa M \& Wakabayashi S 2004 Role of calcineurin $\mathrm{B}$ homologous protein in $\mathrm{pH}$-regulation by the $\mathrm{Na}^{+} / \mathrm{H}^{+}$ exchanger 1: tightly bound $\mathrm{Ca}^{2+}$ ions as important structural elements. Biochemistry 43 3628-3636. (doi:10.1021/bi0360004)

Philip A, Bostedt L, Stigbrand T \& O'Connor-McCourt MD 1994 Binding of transforming growth factor- $\beta$ (TGF- $\beta$ ) to pregnancy zone protein (PZP): comparison to the TGF- $\beta$ - $\alpha 2$-macroglobulin interaction. European Journal of Biochemistry 221 687-693. (doi:10.1111/j.1432-1033.1994. tb18781.x)

Pruitt KD, Tatusova T, Klimke W \& Maglott DR 2009 NCBI reference sequences: current status, policy and new initiatives. Nucleic Acids Research 37 D32-D36. (doi:10.1093/nar/gkn721)

Robertson SA 2007 Seminal fluid signaling in the female reproductive tract: lessons from rodents and pigs. Journal of Animal Science 85 E36-E44. (doi:10.2527/jas.2006-578)

Robertson SA, Mau VJ, Hudson SA \& Tremellen KP 1997 Cytokineleukocyte networks and the establishment of pregnancy. American Journal of Reproductive Immunology 37 438-442. (doi:10.1111/j.16000897.1997.tb00257.x)

Rodriguez-Martinez H 2007 Role of the oviduct in sperm capacitation. Theriogenology 68S S138-S146. (doi:10.1016/j.theriogenology.2007. 03.018) 
Rodriguez-Martinez H, Ekstedt E \& Einarsson S 1990 Acidification of the epididymal fluid in the boar. International Journal of Andrology $\mathbf{1 3}$ 238-243. (doi:10.1111/j.1365-2605.1990.tb00982.x)

Rubin CJ, Zody MC, Eriksson J, Meadows JRS, Sherwood E, Webster MT, Jiang I, Ingman M, Sharpe T, Ka S et al. 2010 Whole-genome resequencing reveals loci under selection during chicken domestication. Nature 464 587-591. (doi:10.1038/nature08832)

Sasanami T, Matsuzaki M, Mizushima S \& Hiyama G 2013 Sperm storage in the female reproductive tract in birds. Journal of Reproduction and Development 59 334-338. (doi:10.1262/jrd.2013-038)

Skornicka EL, Kiyatkina N, Weber MC, Tykocinski ML \& Koo PH 2004 Pregnancy zone protein is a carrier and modulator of placental protein14 in T-cell growth and cytokine production. Cellular Immunology 232 144-156. (doi:10.1016/j.cellimm.2005.03.007)
Soderling SH \& Beavo JA 2000 Regulation of cAMP and cGMP signaling: new phosphodiesterases and new functions. Current Opinion in Cell Biology 12 174-179. (doi:10.1016/S0955-0674(99)00073-3)

Volanakis JE 2002 The role of complement in innate and adaptive immunity. Current Topics Microbiology and Immunology 266 41-56.

Westhoff CM, Siegel DL, Burd CG \& Foskett JK 2004 Mechanism of genetic complementation of ammonium transport in yeast by human erythrocyte Rh-associated glycoprotein. Journal of Biological Chemistry 279 17443-17448. (doi:10.1074/jbc.M311853200)

Revised manuscript received 10 August 2015 Accepted 8 September 2015 